\title{
AN APPROACH TO REPRESENT A COMBINED EXPOSURE TO AIR POLLUTION
}

\section{MIECZYSŁAW SZYSZKOWICZ}

Health Canada, Ottawa, Canada

Population Studies Division

\begin{abstract}
Objectives: The objective of this study was to present a technique for estimating the effect of ambient air pollution mix on health outcomes. Material and Methods: We created a technique of indexing air pollution mix as a cause of the increased odds of health problems. As an illustrative example, we analyzed the impact of pollution on the frequency of emergency department (ED) visits due to colitis among young patients (age < 15 years, $\mathrm{N}=11110$ ). Our technique involves 2 steps. First, we considered 6 ambient air pollutants (carbon monoxide, nitrogen dioxide, sulphur dioxide, ozone, and 2 measures of particulate matter) treating each pollutant as a single exposure. Odds ratios (ORs) for ED visits associated with a standard increase (interquartile range - IQR) in the pollutants levels were calculated using the case-crossover technique. The ORs and their $95 \%$ confidence intervals (95\% CIs) were also found for lagged exposures (for lags 1-9 days). Second, we defined a Health Air Study Index (HASI) to represent the combined impact of the 6 air pollutants. Results: We obtained positive and statistically significant results for individual air pollutants and among them the following estimations: $\mathrm{OR}=1.06$ (95\% CI: 1.02-1.1, $\mathrm{NO}_{2}$ lag 3, IQR = $\left.12.8 \mathrm{ppb}\right), \mathrm{OR}=1.04$ (95\% CI: 1.01-1.07, $\mathrm{SO}_{2}$ lag 4, IQR = $\left.2.3 \mathrm{ppb}\right)$, $\mathrm{OR}=1.04\left(95 \% \mathrm{CI}: 1-1.06\right.$, PM lag 3, IQR $\left.=6.2 \mu \mathrm{g} / \mathrm{m}^{3}\right)$. Among the re-calculated ORs with the HASI values as an exposure, the highest estimated value was OR $=1.37$ (95\% CI: $1.12-1.68$, for 1 unit of the HASI, lag 3). Conclusions: The proposed index (HASI) allows to confirm the pattern of associations for lags obtained for individual air pollutants. In the presented example the used index (HASI) indicates the strongest relation with the exposure lagged by 3 days.
\end{abstract}

Key words:

Ambient air pollution, Case-crossover, Odds ratio, Index, Emergency department visit, Air pollution

\section{INTRODUCTION}

Air pollution is a modifiable health risk factor. It has been shown to be associated with the increased morbidity and mortality, but health effects of air pollution are not limited to cardiac and respiratory health conditions [1-3]. Statistical techniques are used to investigate associations between health outcomes and air pollution, with adjustments for other environmental factors. There are many possible approaches in environmental epidemiology for representing exposure to ambient air pollution, most of them incorporating levels of ambient concentrations of pollutants into the considered models. Usually, statistical models are constructed with a single air pollutant. The pollutant may also be considered jointly with its lags in order to determine potentially delayed health impact [4].

Thus, conclusions regarding associations between air pollution and health are usually derived from single-pollutant modeling of public health parameters, with some minor input from 2-pollutant models for the same health outcome. However, atmospheric air pollution is a complex mixture of different individual pollutants, which are strongly correlated $[5,6]$. Therefore, we consider a method of combining several air pollutants and investigate the relation between

Received: July 9, 2014. Accepted: January 8, 2015.

Corresponding author: M. Szyszkowicz, Health Canada, 200 Eglantine Driveway, Ottawa, ON, K1A 0K9, Canada (e-mail: mietek.szyszkowicz@hc-sc.gc.ca). 
our formed multi-pollutant exposure index - which we call the Health Air Study Index (HASI) - and public health. We modeled health parameters with the HASI exposure index to confirm the results derived from the single-pollutant models.

The proposed HASI index is very similar conceptually to the Air Quality Health Index (AQHI) presented by Stieb et al. [7]; this index is a risk communication tool operational in Canadian cities. It is constructed as a weighted sum of excess mortality risks associated with 3 individual pollutants: nitrogen dioxide $\left(\mathrm{NO}_{2}\right)$, ozone $\left(\mathrm{O}_{3}\right)$ and particulate matter (PM). The pollutants' weights are the coefficients from Poisson models incorporating 3-h moving average concentrations of the hourly levels of the pollutants. A similar idea has been implemented in Hong Kong, China. On the corresponding web page [8] we read the following description: "The AQHI of the current hour is calculated from the sum of the percentage excess risk of daily hospital admissions attributable to the 3-h moving average concentrations of 4 criteria air pollutants: ozone, nitrogen dioxide, sulphur dioxide, and particulate matter (including $\mathrm{PM}_{10}$ and $\mathrm{PM}_{2.5}$ whichever has a higher risk) measured at each air quality monitoring station of the Environmental Protection Department.”

Our main goal was to examine the effects of ambient air pollution on the frequency of Emergency Department (ED) visits due to colitis when the pollution is defined by a mixture of air pollutants, and to compare the results with estimations obtained from the single-pollutant models. The health parameter examined in this study is the frequency of ED visits due to colitis in the population of children aged 0 to 14 years. Previous research has reported associations between air pollution and this particular symptom $[9,10]$; we obtained analogous positive and statistically significant associations for several of the examined in our study air pollutants, and for their mixture occurring in the HASI definition. The results included in this work are not meant to represent scientific findings on ED visits due to colitis, but are presented as an illustrative example for the use of the HASI index.

\section{MATERIAL AND METHODS}

\section{Health data}

The public health effect was represented by the frequency of ED visits due to colitis among patients younger than 15 years of age and served by 5 hospitals in Edmonton over the period from April 17, 1998 to March 31, 2002 (1379 days with complete health, pollution, and climate data). All the 5 hospitals operated in the city of Edmonton. The disease codes from the International Classification of Disease (ICD) 9th Revision (ICD-9), World Health Organization, 1978, were applied to identify the cases classified as colitis, which has ICD-9 code value of 558.9 (i.e., "Other and unspecified noninfectious gastroenteritis and colitis").

\section{Air pollution data}

Ambient air pollution data were supplied by the Environment Canada [11]. In this study we considered ozone $\left(\mathrm{O}_{3}\right)$, carbon monoxide $(\mathrm{CO})$, nitrogen dioxide $\left(\mathrm{NO}_{2}\right)$, sulphur dioxide $\left(\mathrm{SO}_{2}\right)$, and 2 kinds of particulate matter (of median aerodynamic diameter no greater than $2.5 \mu \mathrm{m}\left(\mathrm{PM}_{2.5}\right)$ and $\left.10 \mu \mathrm{m}\left(\mathrm{PM}_{10}\right)\right)$. The daily mean of a pollutant was defined locally as an average of its 24 hourly readings recorded by a local pollution monitoring station. Daily ambient exposure was represented by the average of daily means across 3 monitoring stations that were in operation in Edmonton during the study time interval [12]. The maximum distance between the stations was $11 \mathrm{~km}$. Lagging was applied to the daily ambient exposure to the individual pollutants (lags 0-9 days).

\section{Climate data}

The Environment Canada's climate archive [13] supplied data for selected weather variables, recorded hourly. In this study only 2 meteorological variables were used, 
i.e., ambient temperature (dry bulb) and relative humidity. The daily means (of 24 hourly measurements) represented the climate parameters; natural splines of them were used as confounders in the model.

\section{Statistical method}

In this study a case-crossover (CC) design was applied. The technique is an adaptation of the case-control methodology [14]. In the CC approach, a case defines its own controls, i.e., the case itself considered on a predefined set of control days proximate to the time of the occurrence of the case. Usually, the control days are selected to be the same days of the week in a month of the case occurrence. In such an approach 3 or 4 controls are produced for each case. For example the case on January 8, 2002 has the following 4 corresponding control days: January 1, 15, 22, and 29 in the year 2002. The method has been widely adopted, as it has been shown to produce unbiased conditional logistic regression estimates $[15,16]$.

A $p<0.05$ was considered statistically significant in all the presented statistical results. The results are reported as odds ratios (ORs) with the corresponding 95\% confidence intervals $(95 \% \mathrm{CI})$. The values of ORs are reported in percentages of increase of the odds per increase in the concentration of the air pollutant by one interquartile range (IQR, IQR $=75-25$ th percentile). All statistical calculations were performed using the SAS (version 9.3) statistical software. The estimations of the odds ratios were obtained using the PHREG procedure applied to realize the conditional logistic regression.

\section{Combined exposure and HASI index}

The proposed approach is innovative in the domain of health risk indexing. It is executed in 2 steps.

\section{Step 1}

We considered each air pollutant separately, calculating the interquartile range for each of the 6 pollutants under the study. We normalized the air pollution data with IQR, i.e., we divided each daily value (in our case, the daily mean) of a pollutant by its IQR value. We applied conditional logistic regression models to perform the case-crossover analysis, adopting the usual method of selecting control days in a month of the case occurrence. The models were constructed adjusting for temperature and relative humidity, and lagging the pollution variables by 0 to 9 days. For each lag the model was fitted separately. A model gives a slope, or beta, representing the rate of odds increase (increase in the frequency of ED visits) per a pollutant's concentration increase. Thus, we obtained 10 slopes (lags 0-9) for each air pollutant. The models also specify corresponding ORs and their 95\% CIs per 1-IQR increase in a pollutant concentration.

\section{Step 2}

In the 2nd step we calculated the Health Air Study Index (HASI) for each day $\mathrm{k}$ according to the following formula:

$$
\operatorname{HASI}(\mathrm{k})=\sum_{\mathrm{i}=1}^{\mathrm{m}} \exp (\beta(\mathrm{i}) \times \operatorname{air} \operatorname{pollutant}(\mathrm{k}, \mathrm{i}))-\mathrm{m}
$$

where:

$\mathrm{m}$ - number of air pollutants (here $\mathrm{m}=6$ ),

$\mathrm{i}-$ enumerates the pollutants,

$\beta(\mathrm{i})$ - the largest slope among the 10 slopes estimated for the lags $0-9$ of the pollutant, air pollutant $(\mathrm{k}, \mathrm{i})$ - the pollutant $\mathrm{i}$ on day $\mathrm{k}$ scaled by its IQR.

The HASI values encapsulate health effects of 6 air pollutants, by combining the rates of health aggravation (slopes $\beta(\mathrm{i})$ ) with the current daily levels of the pollutants. The HASI $(\mathrm{k})$ index is a measure of the risk, for day $\mathrm{k}$, of an aggravation of symptoms of colitis caused by air pollution. Odds ratios (ORs) and their 95\% CIs are computed for HASI in the same manner as it was done for the pollutants. 


\section{RESULTS}

Emergency department visits due to colitis totaled 11110 cases (males: $\mathrm{N}=6005,54 \%$; females: $\mathrm{N}=5105,46 \%$ ). The patients $<4$ years of age accounted for $67 \%$ of all the cases. The monthly volume of visits varied from a low (4.3\% of the total) in September months to a high (13.6\% of the total) in March months, across the 114 months covered by the study period. In a similar fashion, Sundays accounted for $19 \%$, compared to $12 \%$ for Thursdays.

Table 1 presents the largest $\beta$ among the slopes ( $\beta$ s) estimated for the pollutant's lags of 0 to 9 days for each pollutant. These slopes were used in calculating the HASI values. Table 1 also shows the ORs and their corresponding 95\% CIs evaluated for an increase of exposure by 1 IQR. Figure 1 illustrates the estimations of ORs and their $95 \%$ CIs for all the considered air pollutants and across all the lags.

Table 2 lists the estimated slopes ( $\beta \mathrm{s})$ for the HASI parameter, for all the considered lags 0 to 9 . The table also shows ORs and the CIs for 1 unit increase in the HASI value. Figure 2 is related to the table; its right-hand part shows the values of the ORs and the CIs. The left-hand side shows the distribution of the HASI values (for 1379 days) with fitted gamma distribution (line).

Table 1. The strongest effects for 6 individual air pollutants

\begin{tabular}{lccccccc}
\hline \multicolumn{1}{r}{ Air } & Lag & $\beta$ & SE & $p$ & OR & $95 \%$ CI & IQR \\
\hline $\mathrm{PM}_{10}$ & 3 & 0.035 & 0.014 & 0.012 & 1.04 & $1.01-1.06$ & 15.0 \\
$\mathrm{PM}_{2.5}$ & 3 & 0.027 & 0.012 & 0.033 & 1.03 & $1.00-1.05$ & 6.2 \\
$\mathrm{CO}$ & 3 & 0.030 & 0.016 & 0.054 & 1.03 & $1.00-1.06$ & 0.4 \\
$\mathrm{NO}_{2}$ & 3 & 0.061 & 0.019 & 0.002 & 1.06 & $1.02-1.10$ & 12.8 \\
$\mathrm{SO}_{2}$ & 4 & 0.038 & 0.016 & 0.016 & 1.04 & $1.01-1.07$ & 2.3 \\
$\mathrm{O}_{3}$ & 6 & 0.024 & 0.028 & 0.380 & 1.02 & $0.97-1.08$ & 14.0 \\
\hline
\end{tabular}

$\mathrm{PM}_{10}$ - particulate matter of median aerodynamic diameter no greater than $10 \mu \mathrm{m} ; \mathrm{PM}_{2.5}$ - particulate matter of median aerodynamic diameter no greater than $2.5 \mu \mathrm{m} ; \mathrm{CO}$ - carbon monoxide; $\mathrm{NO}_{2}$ - nitrogen dioxide; $\mathrm{SO}_{2}$ - sulphur dioxide; $\mathrm{O}_{3}$ - ozone.

$\mathrm{Lag}$ - delay in days; $\beta$ - slope; SE - standard error; OR - odds ratio; CI - confidence interval; IQR - interquartile range.

Table 2. The results for the Health Air Study Index (HASI)

\begin{tabular}{lccccc}
\hline \multicolumn{1}{c}{ Lag } & $\beta$ & SE & $p$ & OR & $95 \%$ CI \\
\hline 0 & 0.048 & 0.108 & 0.655 & 1.05 & $0.85-1.30$ \\
1 & 0.164 & 0.106 & 0.122 & 1.18 & $0.96-1.45$ \\
2 & 0.190 & 0.105 & 0.070 & 1.21 & $0.98-1.49$ \\
3 & 0.317 & 0.102 & 0.002 & 1.37 & $1.12-1.68$ \\
4 & 0.237 & 0.104 & 0.023 & 1.27 & $1.03-1.55$ \\
5 & 0.164 & 0.105 & 0.118 & 1.18 & $0.96-1.45$ \\
6 & 0.012 & 0.106 & 0.909 & 0.99 & $0.80-1.22$ \\
7 & 0.106 & 0.108 & 0.323 & 1.11 & $0.90-1.37$ \\
8 & 0.101 & 0.108 & 0.349 & 1.11 & $0.90-1.37$ \\
9 & 0.166 & 0.107 & 0.119 & 1.18 & $0.96-1.46$ \\
\hline
\end{tabular}

Abbreviations as in Table 1. 


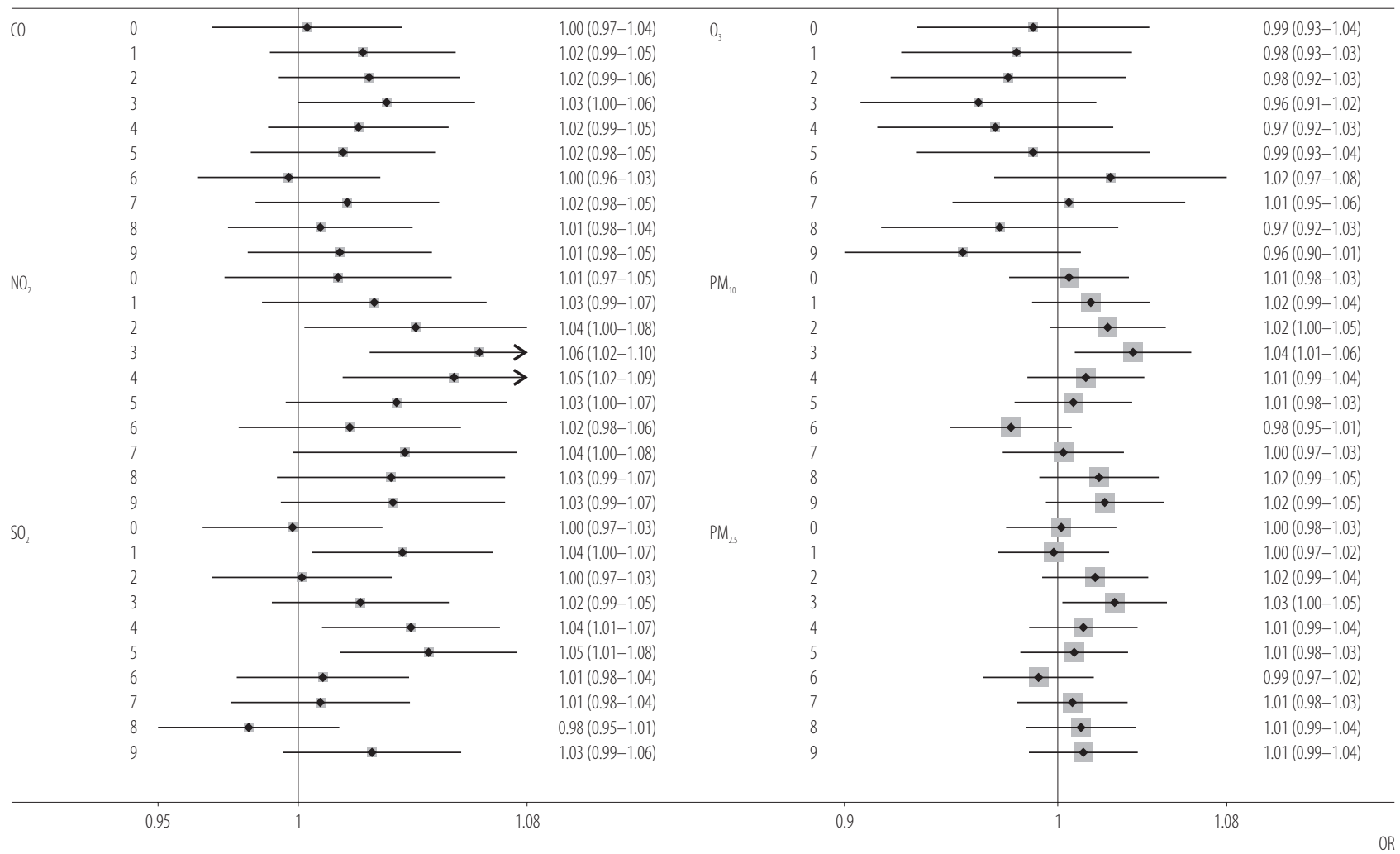

Abbreviations as in Table 1.

Fig. 1. The results for 6 individual air pollutants
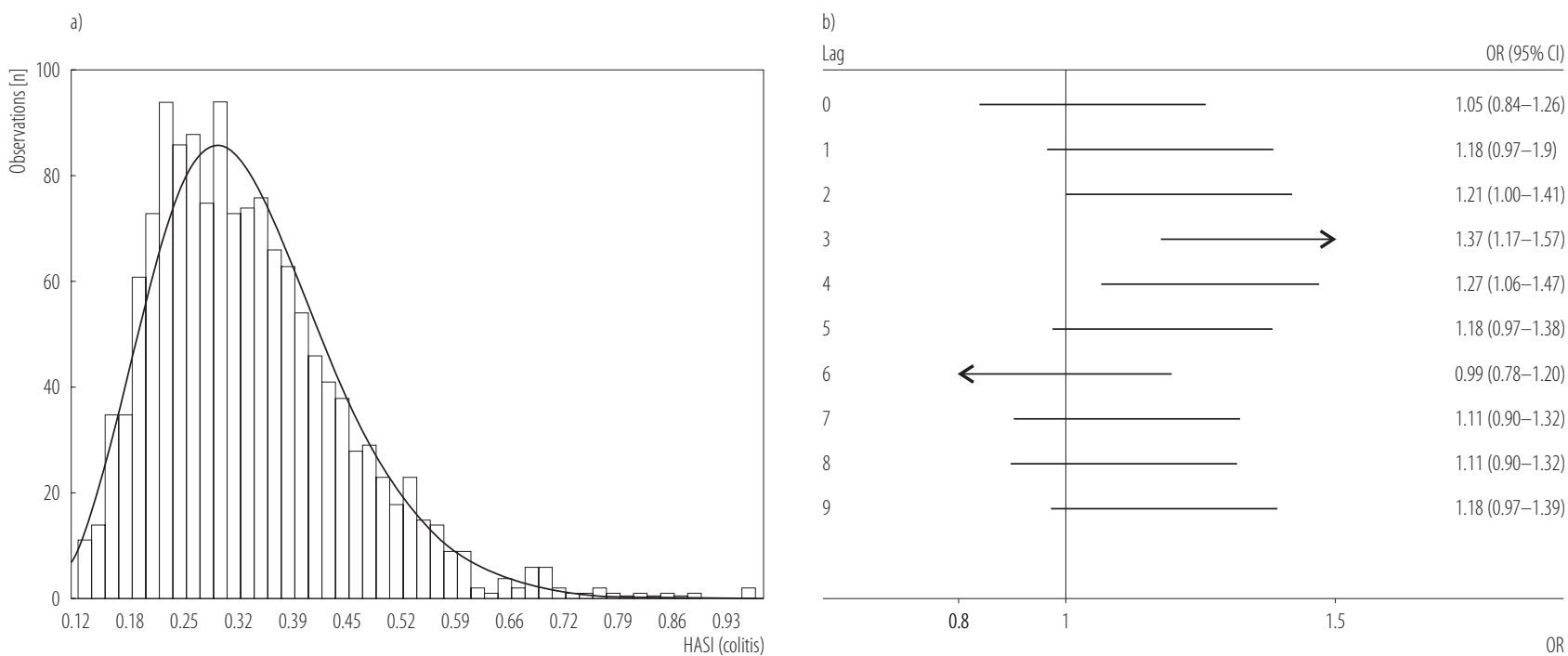

Abbreviations as in Table 1.

Fig. 2. The Health Air Study Index (HASI) values: a) frequency distribution, b) estimated effects for 1 unit increase 
Table 3. Correlations between air pollutants and indexes

\begin{tabular}{lccccccccc}
\hline \multicolumn{1}{c}{ Variable } & $\mathrm{PM}_{10}$ & $\mathrm{PM}_{2.5}$ & $\mathrm{CO}$ & $\mathrm{NO}_{2}$ & $\mathrm{SO}_{2}$ & $\mathrm{O}_{3}$ & $\mathrm{HASI}$ & $\mathrm{AQHI}^{\mathrm{a}}$ & $\mathrm{AQHI}^{\mathrm{m}}$ \\
\hline $\mathrm{PM}_{10}$ & 1 & 0.76 & 0.32 & 0.33 & 0.22 & 0.05 & 0.74 & 0.61 & 0.64 \\
$\mathrm{PM}_{2.5}$ & & 1 & 0.44 & 0.40 & 0.21 & -0.08 & 0.75 & 0.69 & 0.71 \\
$\mathrm{CO}$ & & 1 & 0.84 & 0.37 & -0.58 & 0.77 & 0.58 & 0.58 \\
$\mathrm{NO}_{2}$ & & & & 1 & 0.42 & -0.53 & 0.81 & 0.74 & 0.67 \\
$\mathrm{SO}_{2}$ & & & & & 1 & -0.21 & 0.59 & 0.30 & 0.30 \\
$\mathrm{O}_{3}$ & & & & & & 1 & -0.25 & 0.08 & 0.02 \\
$\mathrm{HASI}$ & & & & & & & & 0.86 & 0.83 \\
$\mathrm{AQHI}^{\mathrm{a}}$ & & & & & & & & 1 & 0.90 \\
$\mathrm{AQHI}^{\mathrm{m}}$ & & & & & & & & & \\
\hline
\end{tabular}

$\mathrm{AQHI}^{\mathrm{a}}$ - daily average of the Air Quality Health Index (AQHI) values; $\mathrm{AQHI}{ }^{\mathrm{m}}$ - maximum of the Air Quality Health Index (AQHI) values. Other abbreviations as in Table 1 and 2.

Table 3 shows correlations between the considered 6 air pollutants, the HASI index, and the $\mathrm{AQHI}^{\mathrm{a}}$ and $\mathrm{AQHI}^{\mathrm{m}}$ indexes: daily mean and maximum, respectively, of the rolling 3-h AQHI values.

\section{DISCUSSION AND CONCLUSIONS}

In this study we proposed a relatively simple method for investigating associations between health outcomes and the joint effect of ambient air pollution exposures. This methodology has already been applied in the implementation of the AQHI risk communication tool [7,8,17-22]. In general, the main idea of such methods is to combine exposure levels and estimated coefficients related to health. The coefficients are used to weigh the pollution parameters. In the AQHI definition, the coefficients are fixed: they are estimated, for each large Canadian city, based on the count of non-accidental deaths in the city due to air pollution. This allows one to treat the AQHI as a universal risk index relating to a large spectrum of health conditions. However, a high AQHI index implies aggravation of health problems in the population of elderly people, while the HASI index is intended to convey information about health risks in children, at least in the presented example.
The main issue in the research concerning indexes of public health risks is the problem of how to generate health coefficients (weights for pollution parameters) also for other health outcomes besides mortality. This study is an example of indexing risks of an increased frequency of ED visits (due to colitis) caused by 6 air pollutants acting immediately or with delays. Generally, risk indexes should encapsulate ambient air conditions that are potentially harmful to health of the targeted population.

One, robust approach to defining a universal index is to collect all the recorded and published slopes for different air pollutants. Next, for any individual air pollutant, 1 slope can be created by taking the mean, median, or other statistical location characteristic of the collected slope sample. Then, one needs to use the chosen slope value to weigh the corresponding air pollutant. Index created in such a way is no longer dedicated to a specific health condition and is not study specific. Extreme values of the slopes may be used to determine the scale for the created index. Publication of health risk indexes is an important part of public health programmes, but designing a reliable index requires numerous studies conducted to determine the best approach. 
We can see in Table 3 that the values of the 3 risk indexes are highly correlated. This is because all of them tend to describe the same reality: risk of public health deterioration due to air pollution. When we destroy links to the reality by generating random slopes, the strong correlations disappear. Indeed, we calculated the HASI and AQHI indexes with randomly generated betas and obtained the following: when each day had its own set of betas, the correlations between the HASI and AQHI values were 0.1. When there was 1 fixed but random set, the correlation amounted to 0.5 . Some correlations persist even with randomly generated coefficients as air pollutants are correlated.

In the literature there are other known techniques of investigating joint effect of air pollutants. Among the techniques to test for multi-pollutant effects are: dimension reduction, supervised principal components, recursive partitioning, source apportionment, clustering, and classification and regression trees [23].

The estimates, via the HASI indexing, of the health risks computed from the combined exposure to air pollutants are compatible with the pattern of the exposure-health associations obtained from the single-pollutant analysis. Harmful effects of an exposure to a pollutant are delayed by 2, 3 or 4 days, depending on the pollutant; the HASI index shows the strongest relation with the exposure lagged by 3 days. This approach is a new contribution in this field.

\section{REFERENCES}

1. Larrieu S, Lefranc A, Gault G, Chatignoux E, Couvy F, Jouves B, et al. Are the short-term effects of air pollution restricted to cardiorespiratory diseases? Am J Epidemiol. 2009;169(10):1201-8.

2. Kaplan GG, Dixon E, Panaccione R, Fong A, Chen L, Szyszkowicz M, et al. Effect of ambient air pollution on the incidence of appendicitis. CMAJ. 2009;181:591-7, http://dx.doi. org/10.1503/cmaj.082068.

3. Szyszkowicz M, Shutt R, Kousha T, Rowe BH. Air pollution and emergency department visits for epistaxis. Clin
Otolaryngol. 2014;39(6):345-51, http://dx.doi.org/10.1111/ coa.12296.

4. Gasparrini A. Modeling exposure-lag-response associations with distributed lag non-linear models. Stat Med. 2014;33(5):881-99.

5. Szyszkowicz M. Remarks on ambient air pollution and health outcomes. ISRN Public Health. 2013;2013:1-5. Article ID 846297, http://dx.doi.org/10.1155/2013/846297.

6. Szyszkowicz M, Tremblay N. Case-crossover design: Air pollution and health outcomes. Int J Occup Med Environ Health. 2011;24(3):249-55, http://dx.doi.org/10.2478/s13382011-0034-y.

7. Stieb DM, Burnett RT, Smith-Doiron M, Brion O, Shin HH, Economou V. A new multipollutant, no-threshold air quality health index based on short-term associations observed in daily time-series analyses. J Air Waste Manag Assoc. 2008;58(3):435-50.

8. Hong Kong Special Administrative Region Goverment [Internet]. Air Quality Index [cited 2014 Sep 24]. Available from: http:/www.gov.hk/en/residents/environment/air/aqhi.htm.

9. Beamish LA, Osornio-Vargas AR, Wine E. Air pollution: An environmental factor contributing to intestinal disease. J Crohns Colitis. 2011;5:279-86, http://dx.doi. org/10.1016/j.crohns.2011.02.017.

10. Kaplan GG, Szyszkowicz M, Fichna J, Rowe BH, Porada $\mathrm{E}$, Vincent $\mathrm{R}$, et al. Non-specific abdominal pain and air pollution: A novel association. PLoS One. 2012;7(10): e47669, http://dx.doi.org/10.1371/journal.pone.0047669.

11. Environment Canada. Fredericton; Environment Canada [cited 2014 Sep 24]. National Air Pollution Surveillance Program. Available from: http://www.ec.gc.ca/rnspa-naps.

12. Zemek R, Szyszkowicz M, Rowe BH. Air pollution and emergency department visits for otitis media: A case-crossover study in Edmonton, Canada. Environ Health Perspect. 2010;118(11):1631-6, http://dx.doi.org/10.1289/ehp.0901675.

13. Environment Canada. Fredericton; Environment Canada [cited 2014 Sep 24]. Climate. Available from: http://climate. weather.gc.ca/. 
14. Maclure M. The case-crossover design: A method for studying transient effects on the risk of acute events. Am J Epidemiol. 1991;133(2):144-53.

15. Janes H, Sheppard L, Lumley T. Case-crossover analyses of air pollution exposure data. Referent selection strategies and their implications for bias. Epidemiology. 2005;16(6):717-26.

16. Wang SV, Coull BA, Schwartz J, Mittleman MA, Wellenius GA. Potential for bias in case-crossover studies with shared exposures analyzed using SAS. Am J Epidemiol. 2011;174(1):118-24, http://dx.doi.org/10.1093/aje/kwr038.

17. To T, Shen S, Atenafu EG, Guan J, McLimont S, Stocks B, et al. The Air Quality Health Index and asthma morbidity: A population-based study. Environ Health Perspect. 2013; 121(1):46-52, http://dx.doi.org/10.1289/ehp.1104816.

18. Szyszkowicz M, Kousha T. Emergency department visits for asthma in relation to the Air Quality Health Index: A case-crossover study in Windsor. Can J Public Health. 2014;105(5):e336-41.

19. Abelsohn A, Stieb DM. Health effects of outdoor air pollution: Approach to counseling patients using the Air
Quality Health Index. Can Fam Physician. 2011;57(8): 881-7, e280-7.

20. Chen R, Wang X, Meng X, Hua J, Zhou Z, Chen B, et al. Communicating air pollution-related health risks to the public: An application of the Air Quality Health Index in Shanghai, China. Environ Int. 2013;51:168-73, http:/ dx.doi.org/10.1016/j.envint.2012.11.008.

21. Chen L, Villeneuve PJ, Rowe BH, Liu L, Stieb DM. The Air Quality Health Index as a predictor of emergency department visits for ischemic stroke in Edmonton, Canada. J Expo Sci Environ Epidemiol. 2014;24(4):358-64, http:// dx.doi.org/10.1038/jes.2013.82.

22. Kousha T. Valacchi G. The air quality health index and emergency department visits for urticaria in Windsor, Canada. J Toxicol Environ Health A. 2015;78(8):524-33, http://dx.doi.org/10.1080/15287394.2014.991053.

23. Gass K, Klein M, Chang HH, Flanders WD, Strickland MJ. Classification and regression trees for epidemiologic research: An air pollution example. Environ Health. 2014 Mar 13;13(1):17, http://dx.doi.org/10.1186/1476-069X-13-17.

This work is available in Open Access model and licensed under a Creative Commons Attribution-NonCommercial 3.0 Poland License - http://creativecommons.org/ licenses/by-nc/3.0/pl/deed.en. 